\title{
BMJ Open Do smoking habits differ between women and men in contemporary Western populations? Evidence from half a million people in the UK Biobank study
}

\author{
Sanne A E Peters, ${ }^{1}$ Rachel R Huxley, ${ }^{2}$ Mark Woodward ${ }^{1,3,4}$
}

To cite: Peters SAE, Huxley RR, Woodward M. Do smoking habits differ between women and men in contemporary Western populations? Evidence from half a million people in the UK Biobank study. BMJ Open 2014:4:e005663.

doi:10.1136/bmjopen-2014005663

- Prepublication history and additional material is available. To view please visit the journal (http://dx.doi.org/ 10.1136/bmjopen-2014005663)

Received 8 May 2014 Revised 23 October 2014 Accepted 24 November 2014

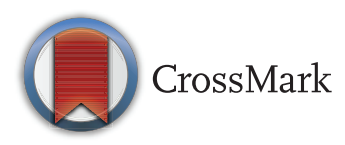

For numbered affiliations see end of article.

Correspondence to Professor Mark Woodward; mark.woodward@ georgeinstitute.0x.ac.uk

\section{ABSTRACT}

Objectives: Several studies have shown that smoking may confer a greater excess risk for chronic diseases in women compared with men. The reasons for this excess risk of smoking in women are unclear, yet sex differences in smoking habits may play a role. We, thus, characterised sex differences in smoking habits in a contemporary Western population.

Design: Cross-sectional population-based study.

Setting: UK Biobank Resource.

Participants: 499797 (54\% women) individuals with data on smoking habits.

Main outcome measures: Women-to-men prevalence ratios in smoking status, and the womenminus-men mean difference in age at smoking initiation, number of cigarettes smoked daily and age at smoking cessation in 5-year birth cohort bands.

Results: The women-to-men ever-smoking ratio ranged from 0.57 in the oldest to 0.87 in the youngest birth cohort. In the oldest cohort, born 1935-1939, women started smoking 1.9 years $(95 \% \mathrm{Cl} 1.7$ to 2.1$)$ later than did men, but in those born after 1959 there was no difference in the age at initiation. The oldest women smoked 5.3 ( $95 \%$ Cl 4.7 to 5.9 ) cigarettes per day fewer than did the oldest men, compared with $2.0(95 \% \mathrm{Cl} 1.7$ to 2.3$)$ fewer cigarettes smoked per day in the youngest, born 1965-1969. Among quitters, women born before 1945 were, on average, 1.5 years older than their male contemporaries, but this differential was 1 year or less among people born after 1949.

Conclusions: Differences in smoking behaviour between women and men have decreased over time. Even past differentials are unlikely to explain the increased susceptibility to smoking-related chronic disease in women compared with men that has previously been observed. Future studies are required to determine whether sex differences in the physiological and biological effects of smoking are responsible for the differential impact of smoking on health in women and men.

\section{Strengths and limitations of this study}

- The large amount of information on smoking behaviour from nearly half a million individuals in UK Biobank permits a comprehensive evaluation of sex differences in smoking characteristics among individuals who commenced smoking at different stages of the tobacco epidemic.

- The much lower prevalence of smoking in the UK Biobank sample compared with the UK population (currently $19 \%$ for women and $20 \%$ for men 21) is unsurprising and indicative of the "healthy-volunteer effect". This difference in smoking prevalence does not detract from the study's' internal validity and its main findings that pertain to sex differences in smoking habits.

- Given that over $90 \%$ of participants in UK Biobank are Caucasian, the analyses presented here cannot be generalised to other ethnic groups.

- Our data are right truncated and individuals from younger birth cohorts have had less opportunity to quit smoking compared to individuals from older birth cohorts. While right truncation complicates comparison of time-related variables between birth cohorts, differences between men and women from the same birth cohort are less likely to be affected.

- The cross-sectional nature of our analyses precluded examination of the associations between smoking characteristics and chronic disease outcomes in women and men which can only be examined using longitudinal data; we aim to explore this further in the UK Biobank sample, once sufficient numbers of events have accrued.

\section{INTRODUCTION}

Despite major successes in evidence-based tobacco control over the past 50 years, tobacco exposure remains one of world's major health threats. In the 20th century, an 
estimated 100 million deaths were due to smoking, representing $16 \%$ of deaths among men and $7 \%$ of deaths among women. ${ }^{2}$ It has been predicted that there will be one billion deaths attributable to tobacco in the 21 st century, ${ }^{3}{ }^{4}$ and it is likely that this burden will differentially affect women more than men due to women being at an earlier stage of the tobacco epidemic than men in most parts of the world..$^{5}$

Accumulating evidence from large contemporary studies suggests that the full hazards of prolonged smoking are considerably larger for women than they are for men. ${ }^{6-10}$ For example, several studies have indicated that, for a given number of cigarettes smoked, women may be at higher risk of lung cancer compared with men. ${ }^{6} 11$ Moreover, a recent meta-analysis, involving millions of individuals, showed that, although smoking considerably increased the risk of coronary heart disease (CHD) in both sexes, women who smoke have a $25 \%$ greater excess relative risk for CHD compared with men who smoke. ${ }^{7}$

One possible explanation for these excess relative risks of smoking in women might be that women are more susceptible to the effects of smoking or may extract a greater quantity of carcinogens and other toxic agents from the same number of cigarettes than men. ${ }^{12}$ Alternatively, it might be that smoking habits are more risk-inducing in women than in men, that is, women may start to smoke at a younger age, or may smoke more cigarettes per day than men. Yet, past studies have shown the opposite, that is, that smoking habits might be more risk-inducing in men, ${ }^{13-15}$ which would make the observed excess relative risks of smoking-induced diseases in women even more remarkable. However, past studies varied in the type and amount of data collated on current and past smoking habits and hence may not accurately reflect any sex differences in smoking habits in contemporary populations.

To further understand whether behavioural differences in smoking habits between women and men may explain the smoking-related excess relative risks observed in women in previous studies, and to ultimately inform national and international sex-specific tobacco control policies, we examined the current and past smoking habits of women and men who were recruited into the UK Biobank study.

\section{METHODS}

\section{Data source}

Cross-sectional data were obtained from the UK Biobank, a large-scale, prospective cohort study among 502712 men and women aged 40-69 at baseline. ${ }^{16}{ }^{17}$ Between 2006 and 2010, participants attended 1 of the 22 centres across the UK for detailed baseline assessment that involved collection of extensive questionnaire data, physical measurements and biological samples.

\section{Smoking habits}

Self-report questions on smoking behaviour in the UK Biobank were adapted from various longitudinal epidemiological studies and surveys, after consultation with experts in the field. ${ }^{17}$ These questions solicited comprehensive information on present and past smoking habits, including information on the age of smoking initiation, the number of cigarettes per day, duration of smoking and, among former smokers, the age when smoking ceased. In the present study, smoking status was defined based on regular smoking habits, that is, current smokers were individuals who smoked on most or all days, previous smokers were individuals who had done so in the past, and ever-smokers were these two groups combined. Occasional smokers were classified as never-smokers for the main analyses and analysed separately in secondary analyses.

\section{Statistical analyses}

The outcome metrics were the women-to-men prevalence ratios in smoking status, and the women-minus-men mean differences in age at smoking initiation, number of cigarettes smoked daily, smoking pack-years (cigarettes per day multiplied by the number of years smoked) and age at smoking cessation. The analyses were stratified by 5-year birth cohort ranging from 1935 to 1974 . Results for individuals born 1970-1974 are not reported due to the small size of this birth cohort $(n=168)$. Secondary analyses stratified the same metrics by socioeconomic status (SES), measured by the Townsend material deprivation score, adjusting for age. Five SES groups were defined using the quintiles of the Townsend scores in England from the 2001 Census: ${ }^{18}$ the lower the score the more socially deprived the individual. Multivariable analyses were performed to estimate the extent of differences in smoking habits between men and women according to birth cohort and SES. All analyses were conducted using R software, V.2.15.3. ${ }^{19}$

\section{RESULTS}

Of the 499797 (99.4\%) UK Biobank participants with data on smoking included in the present analyses, $54 \%$ were women. The median year of birth was 1950 (IQR 1945-1958), and they were recruited when, on average, aged 57 years (SD 8 years).

\section{Prevalence of smoking}

Among all participants, 7\% of women and 9\% of men were current daily smokers, $20 \%$ of women and $29 \%$ of men were previous daily smokers. Among those who had never smoked daily, $1 \%$ of women and $2 \%$ of men were current occasional smokers, $11 \%$ of women and $12 \%$ of men were previous occasional smokers, the remaining $59 \%$ of women, and $49 \%$ of men had never smoked, even not occasionally. Irrespective of birth cohort, about one-quarter of all women were ever-smokers (table 1). In contrast, the proportion of ever-smokers in men declined across successive birth cohorts from $46 \%$ of men born 1935-1939 to 28\% of men born 1965-1969. Owing to the lower prevalence of ever-smoking in 


\begin{tabular}{|c|c|c|c|c|c|c|c|}
\hline & \multicolumn{7}{|l|}{ Birth cohort } \\
\hline & 1935-1939 & 1940-1944 & 1945-1949 & 1950-1954 & 1955-1959 & 1960-1964 & 1965-1969 \\
\hline \multicolumn{8}{|l|}{$n$} \\
\hline Women & 9142 & 50345 & 64884 & 48750 & 41839 & 35627 & 21330 \\
\hline Men & 9041 & 47729 & 53661 & 38169 & 32081 & 28492 & 18539 \\
\hline \multicolumn{8}{|l|}{ Smoking status } \\
\hline \multicolumn{8}{|l|}{ Ever-smokers } \\
\hline Women & $2382(26.1)$ & $14589(29.0)$ & $18974(29.2)$ & 13618 (27.9) & $10791(25.8)$ & $8373(23.5)$ & $5126(24.0)$ \\
\hline Men & $4148(45.9)$ & 22236 (46.6) & 22446 (41.8) & $14144(37.1)$ & 10027 (31.3) & $8099(28.4)$ & $5257(28.4)$ \\
\hline Women-to-men ratio & 0.57 & 0.62 & 0.70 & 0.75 & 0.83 & 0.83 & 0.85 \\
\hline \multicolumn{8}{|c|}{ Age at which participant first started to smoke } \\
\hline Women & $19.3(5.0)$ & $18.7(4.6)$ & $18.0(4.2)$ & $17.7(4.4)$ & $17.3(4.3)$ & $17.3(4.5)$ & $17.4(4.3)$ \\
\hline Men & $17.4(4.1)$ & $17.1(4.0)$ & $16.8(4.0)$ & $16.9(4.1)$ & $16.8(4.4)$ & $17.2(4.7)$ & $17.3(4.3)$ \\
\hline Mean difference & $1.9(1.7$ to 2.1$)$ & $1.6(1.5$ to 1.7$)$ & $1.2(1.1$ to 1.2$)$ & $0.9(0.8$ to 1.0$)$ & $0.5(0.3$ to 0.6$)$ & 0.1 (0.0 to 0.3$)$ & $0.1(0.0$ to 0.3$)$ \\
\hline \multicolumn{8}{|c|}{ Cigarettes smoked per day } \\
\hline Women & $16.1(8.6)$ & $16.1(8.6)$ & $16.5(8.5)$ & $16.5(8.1)$ & $16.0(8.1)$ & $15.2(7.9)$ & $14.3(7.5)$ \\
\hline Men & $21.4(12.3)$ & $21.6(12.2)$ & $21.1(11.5)$ & $20.4(10.9)$ & $19.4(10.1)$ & $17.9(9.8)$ & $16.3(8.8)$ \\
\hline Mean difference & $-5.3(-5.9$ to -4.7$)$ & $-5.5(-5.8$ to -5.3$)$ & $-4.7(-4.9$ to -4.5$)$ & $-3.9(-4.1$ to -3.7$)$ & $-3.3(-3.6$ to -3.1$)$ & $-2.6(-2.9$ to -2.4$)$ & $-2.0(-2.3$ to -1.7$)$ \\
\hline \multicolumn{8}{|c|}{ Pack-years of smoking } \\
\hline Women & $20.9(16.5)$ & $20.1(16.2)$ & $20.0(15.6)$ & $18.5(14.1)$ & $16.5(13.4)$ & $13.3(11.5)$ & $10.0(8.9)$ \\
\hline Men & $28.3(22.2)$ & $27.9(21.7)$ & $26.0(20.2)$ & $22.9(18.2)$ & $20.0(16.9)$ & $15.5(14.0)$ & $12.0(11.4)$ \\
\hline Mean difference & $-7.4(-8.5$ to -6.4$)$ & $-7.8(-8.2$ to -7.4$)$ & $-6.0(-6.4$ to -5.7$)$ & $-4.4(-4.8$ to -4.0$)$ & $-3.4(-3.9$ to -3.0$)$ & $-2.1(-2.5$ to -1.7$)$ & $-2.0(-2.4$ to -1.6$)$ \\
\hline \multicolumn{8}{|c|}{ Age at which participant stopped smoking } \\
\hline Women & $46.6(12.8)$ & $44.5(12.3)$ & $40.7(11.9)$ & $37.9(10.9)$ & $36.1(9.7)$ & $34.8(7.8)$ & $33.3(6.3)$ \\
\hline Men & $45.0(12.8)$ & $43.1(12.4)$ & $40.4(11.8)$ & $38.4(10.9)$ & $36.8(9.6)$ & $35.8(7.7)$ & $33.7(6.2)$ \\
\hline Mean difference & 1.6 (0.9 to 2.3$)$ & 1.4 (1.1 to 1.7$)$ & $0.3(0.0$ to 0.5$)$ & $-0.5(-0.8$ to -0.2$)$ & $-0.7(-1.1$ to -0.4$)$ & $-1.0(-1.3$ to -0.7$)$ & $-0.4(-0.7$ to -0.1$)$ \\
\hline \multicolumn{8}{|c|}{$\begin{array}{l}\text { Age is in years. Data are } \mathrm{n}(\%) \text { for categorical variables, and mean (SD) for continuous variables in women and men. Mean difference is the women-minus-men difference (95\% Cl). Data on } \\
\text { age at smoking initiation, cigarettes smoked per day, pack-years of smoking and age at which participant stopped smoking are for current and previous smokers combined. }\end{array}$} \\
\hline
\end{tabular}


Figure 1 Women-to-men ratios of smoking characteristics by birth cohort.

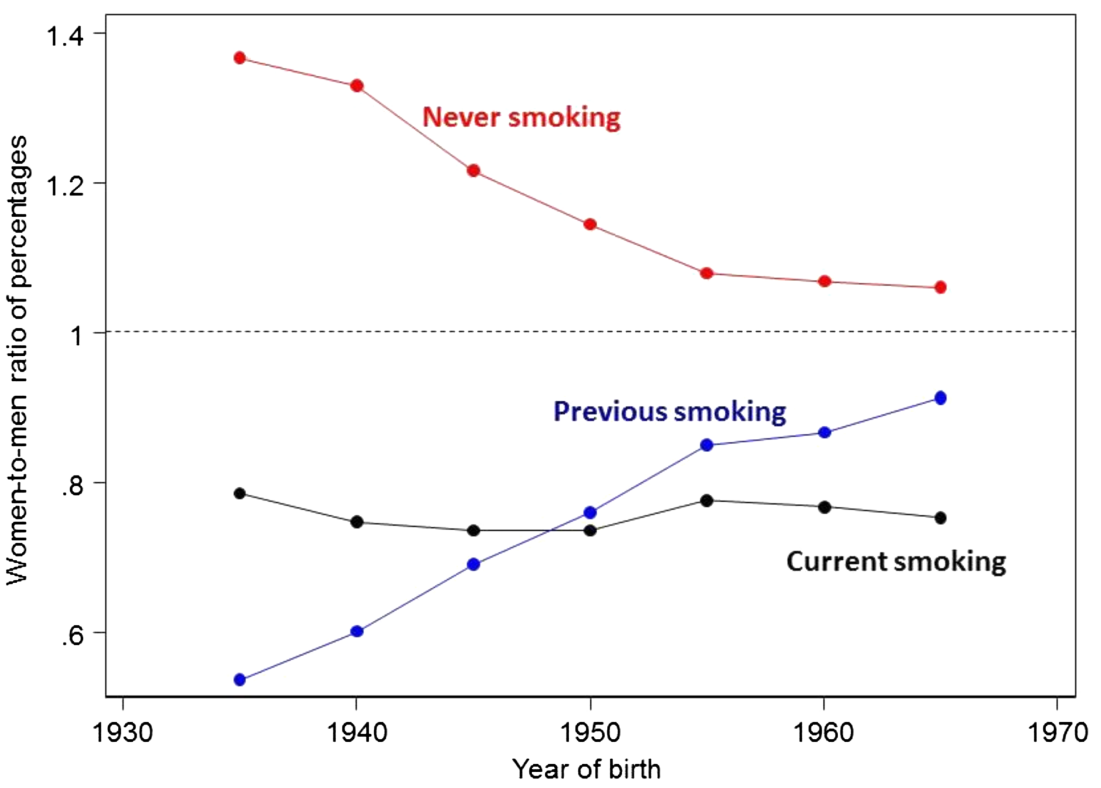

had dropped to 14 and 16 cigarettes per day, respectively (table 1 and figure 2). The mean women-to-men difference in daily cigarette consumption fell from five in the 1935-1939 birth cohort to two in the 1965-1969 cohort. The number of pack-years of smoking was on average 7.7 years higher in men than in women from the 19351939 birth cohort.

The women-to-men difference in pack-years of smoking declined with successive birth cohorts from on average 7.7 pack-years in those born 1935-1939 to 3.2 pack-years in those born 1965-1969.

Women born 1935-1939 who had stopped smoking were on average 1.6 years older than men when they stopped smoking. Women from younger birth cohorts were of the same age or younger than men when they discontinued to smoke (table 1 and figure 2). Results for current and previous smoking are shown in online supplementary table S2.
Figure 2 Mean women-to-men differences in smoking habits by birth cohort.

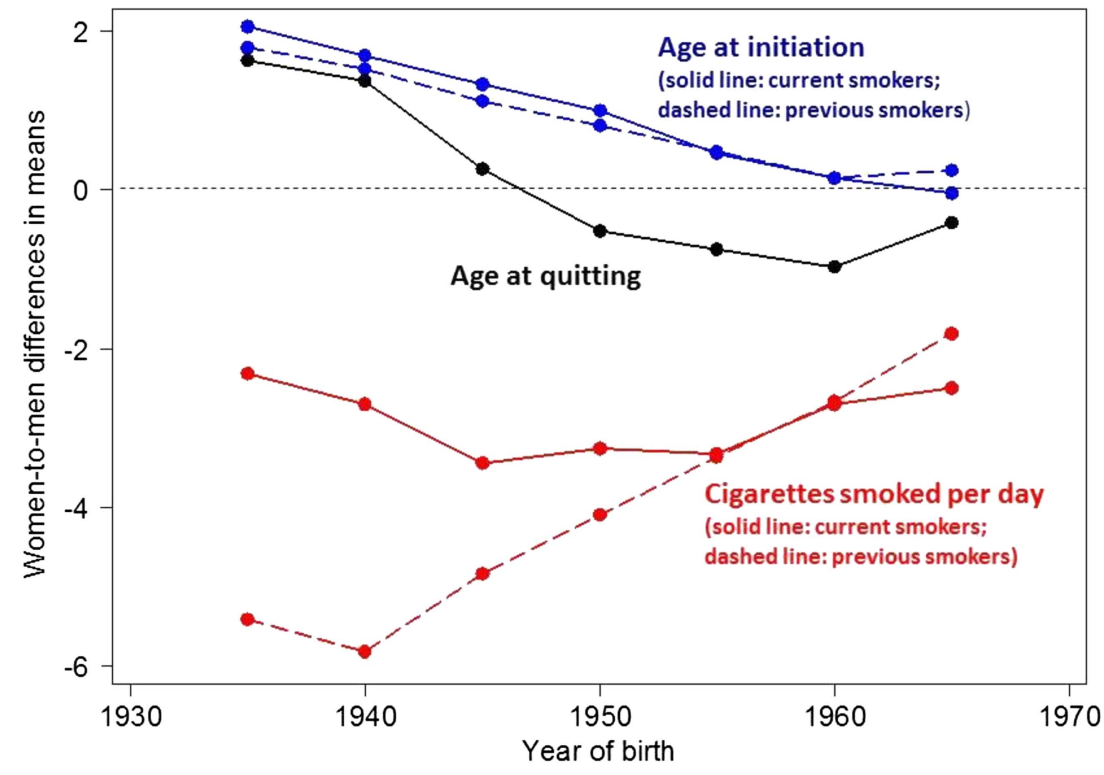




\section{Sex differences in smoking characteristics by SES}

The uptake of ever-smoking was 1.8 times higher in women and 1.5 times higher in men in the most disadvantaged socioeconomic compared with the most advantaged socioeconomic group. While the average age at smoking initiation was similar across socioeconomic groups, the number of cigarettes smoked per day, packyears of smoking and age at smoking cessation were higher in the more disadvantaged socioeconomic groups. Compared with individuals in the least disadvantaged group, those in the most disadvantaged group smoked about two cigarettes per day more, and among previous smokers, they were 5-6 years older when they quit (see online supplementary table S3). There was little evidence to suggest that the sex differences in smoking characteristics observed in the main analyses varied substantially across levels of SES (table 2) or by birth cohort (see online supplementary tables S4-9 and supplementary figures S1-2).

\section{DISCUSSION}

Multiple studies have shown that the excess risk for chronic diseases from smoking is considerably greater in women than in men. ${ }^{6-10}{ }^{20}$ Whether this sex difference is due to more hazardous smoking behaviours in women or a greater susceptibility among women to the toxins in cigarette smoke is unknown. In this study among half a million middle-aged men and women from the UK Biobank, there are some notable differences in how patterns of smoking behaviour have changed over time in women and men. First, age of smoking initiation among women slightly declined (whereas it remained constant in men) over time such that the youngest women in this study began smoking roughly at the same age as men. Second, while the sex difference in the number of cigarettes smoked per day also narrowed across successive birth cohorts (from five to two), women still smoke fewer cigarettes per day than do men and thus will have a lower cumulative lifetime exposure to smoking than men-a finding consistent with nationally representative data. ${ }^{21}$ This finding therefore implies that it is unlikely that more adverse smoking patterns in women compared with men underlie the excess risk in women smokers for some diseases that have been widely reported.

\section{Sex differences in smoking behaviour in the UK Biobank versus other studies}

Sex differences in smoking behaviour reported here are in line with reports on smoking prevalence and cigarette consumption in men and women in the UK and in other parts of the world. ${ }^{2} 1321$ The Global Adult Tobacco Survey (GATS), a nationally representative household survey among three billion individuals from 16 countries, showed that while sex disparities in smoking behaviour still exist, they are considerably smaller in younger individuals, especially in Western populations. ${ }^{13}$ For instance, women aged over 65 years typically started to smoke some 5 years later than men, whereas younger women are starting to smoke at the same age as men. This is of particular concern given the independent and inverse association between age of smoking initiation with chronic disease risk. ${ }^{22}$

As in the UK Biobank, daily cigarette consumption is lower in women than in men in most populations studied, although the difference appears to have diminished over time. ${ }^{13-15}$ For example, women smoke on average four cigarettes per day less than men in the 16 GATS countries. ${ }^{13}$ We have previously reported that women from the Asia-Pacific region have smoked fewer cigarettes than men: an average of 10 vs 15 cigarettes per day in Asia and 16 vs 18 cigarettes per day in Australia and New Zealand. ${ }^{14}$ The US 2004 National Health Interview Survey reported the mean consumption of cigarettes per day as 18.1 in men and 15.3 in women. ${ }^{15}$ Finally, the 2010 smoking statistics in England estimated men to smoke 13.3 cigarettes a day, compared with 12.1 for women. ${ }^{21}$

\section{Sex differences in the prevalence of smoking}

The prevalence of smoking has declined substantially in most parts of the world. In a recent nationally representative study across 187 countries, large reductions in the estimated prevalence of daily smoking were observed between 1980 and 2012; for men, the prevalence decreased from $41 \%$ to $31 \%$, an average annual rate of decline of $0.9 \%$, and for women it decreased from $11 \%$ to $6 \%$, or $1.7 \%$ per year. ${ }^{23}$ These data also illustrate that the global prevalence of smoking is nearly five times as high in men as in women; however, substantial differences between countries exist. ${ }^{24}$ Current smoking rates are virtually the same in women and men living in highincome countries; in the UK, $20 \%$ of men and $19 \%$ of women are current smokers. ${ }^{21}$ Yet, considerable sex differences in smoking prevalence exists in many lowincome and middle-income countries, including countries like India and China, where the women-to-men smoking prevalence ratio is generally less than 0.1. ${ }^{13} 24$

\section{Sex differences in susceptibility for tobacco smoke}

Since sex differences in smoking behaviour do not seem to explain the observed excess risk of smoking in women, it may be that women respond in a biologically different way to smoking than men. Definitive evidence for the biological mechanisms responsible for the sexrelated difference in disease risk associated with smoking is lacking. However, several genetic, biological and hormonal factors have been identified that may be responsible for the greater excess risk of smoking attributed for lung cancer in women. ${ }^{25-27}$ For instance, some studies have found that levels of DNA adducts (pieces of DNA covalently bonded to a cancer-causing chemical that are considered to be the precursor to carcinogenesis) were higher, ${ }^{28}{ }^{29}$ and DNA repair capacity lower, ${ }^{30}$ in female patients with lung cancer compared with their 
Table 2 Smoking habits of ever-smokers by sex and socioeconomic status (SES)

\begin{tabular}{|c|c|c|c|c|c|}
\hline & \multicolumn{5}{|c|}{ Smoking habits by SES, and differences between men and women } \\
\hline & SES 1 & SES 2 & SES 3 & SES 4 & SES 5 \\
\hline \multicolumn{6}{|l|}{$n$} \\
\hline Women & 91342 & 65694 & 48629 & 38502 & 27511 \\
\hline Men & 76903 & 53668 & 39357 & 31966 & 25603 \\
\hline \multicolumn{6}{|l|}{ Smoking status } \\
\hline \multicolumn{6}{|l|}{ Ever smokers } \\
\hline Women & $19710(21.6)$ & $16354(24.9)$ & $13964(28.7)$ & $12892(33.5)$ & $10858(39.5)$ \\
\hline Men & 25591 (33.3) & $19301(36.0)$ & $15178(38.6)$ & 13705 (42.9) & $12504(48.8)$ \\
\hline Women-to-men ratio & 0.65 & 0.69 & 0.74 & 0.78 & 0.81 \\
\hline \multicolumn{6}{|c|}{ Age at which participant first started to smoke } \\
\hline Women & $18.0(4.1)$ & $17.9(4.3)$ & $17.9(4.5)$ & $17.9(4.7)$ & $17.7(4.9)$ \\
\hline Men & $17.1(3.7)$ & $17.0(3.9)$ & $16.9(4.1)$ & $17.0(4.5)$ & $16.9(5.0)$ \\
\hline Mean difference & $1.0(0.9$ to 1.0$)$ & $1.0(0.9$ to 1.1$)$ & $1.0(0.9$ to 1.1$)$ & $0.9(0.8$ to 1.0$)$ & $0.8(0.6$ to 0.9$)$ \\
\hline \multicolumn{6}{|c|}{ Cigarettes smoked per day } \\
\hline Women & $15.3(7.7)$ & $15.7(8.0)$ & $16.1(8.2)$ & $16.5(8.6)$ & $17.2(9.2)$ \\
\hline Men & $19.7(10.5)$ & $20.0(10.6)$ & $20.1(10.9)$ & $20.8(12.1)$ & $21.5(12.9)$ \\
\hline Mean difference & $-4.3(-4.4$ to -4.1$)$ & $-4.2(-4.4$ to -4.0$)$ & $-3.9(-4.1$ to -3.7$)$ & $-4.1(-4.4$ to -3.9$)$ & $-4.2(-4.5$ to -3.9$)$ \\
\hline \multicolumn{6}{|l|}{ Pack-years of smoking } \\
\hline Women & $17.5(13.5)$ & $17.5(14.2)$ & $17.5(14.6)$ & $18.0(15.3)$ & $19.1(16.7)$ \\
\hline Men & $23.1(18.1)$ & $23.0(18.6)$ & $22.7(18.9)$ & $23.4(20.6)$ & $25.3(23.2)$ \\
\hline Mean difference & $-4.9(-5.2$ to -4.6$)$ & $-4.9(-5.2$ to -4.5$)$ & $-4.7(-5.1$ to -4.3$)$ & $-4.9(-5.4$ to -4.5$)$ & $-6.0(-6.5$ to -5.5$)$ \\
\hline \multicolumn{6}{|c|}{ Age at which participant stopped smoking } \\
\hline Women & $37.9(11.4)$ & $39.0(11.6)$ & $39.8(11.4)$ & $40.8(11.6)$ & $42.9(11.4)$ \\
\hline Men & $38.9(11.5)$ & $39.7(11.6)$ & $40.2(11.5)$ & $41.5(11.7)$ & $42.8(11.6)$ \\
\hline Mean difference & $-0.2(-0.5$ to 0.0$)$ & $0.0(-0.2$ to 0.3$)$ & $0.2(-0.1$ to 0.5$)$ & $0.1(-0.2$ to 0.4$)$ & $0.6(0.2$ to 1.0$)$ \\
\hline
\end{tabular}


male counterparts, even after adjustment for smoking dose. This suggests that women may be more susceptible to the DNA damaging effects of tobacco smoke than men. Some, ${ }^{28} 31{ }^{32}$ but not all, ${ }^{33}$ studies also identified sex differences in the frequency of mutations in tumour suppressor genes, with higher frequencies seen among women than men. Furthermore, it may be that women extract a greater quantity of carcinogens and other toxic agents from the same number of cigarettes than men, which again might explain why smoking confers a greater excess risk in women than in men. ${ }^{12}$ Lastly, female-specific factors or hormonal differences may explain the greater excess risk from smoking for lung cancer risk in women, ${ }^{34} 35$ yet evidence has been inconsistent and the possible mediating role of smoking remains unclear.

\section{CONCLUSIONS}

Although there are differences in smoking behaviour between women and men, these cannot explain the increased susceptibility to smoking-related chronic disease in women compared with men that has been repeatedly observed. Future studies that are able to explore the sex-specific physiological and biological effects of smoking are warranted in order to improve current understanding of the differential impact of smoking on health in women and men.

\section{Author affiliations}

${ }^{1}$ Nuffield Department of Population Health, The George Institute for Global Health, University of Oxford, Oxford, UK

${ }^{2}$ School of Population Health, University of Queensland, Brisbane, Australia

${ }^{3}$ The George Institute for Global Health, University of Sydney, Sydney, Australia

${ }^{4}$ Department of Epidemiology, Johns Hopkins University, Baltimore, Maryland, USA

Acknowledgements This research has been conducted using the UK Biobank Resource.

Contributors SAEP wrote the first draft of the article and performed statistical analyses. RRH commented critically on the manuscript. MW conceived the research and produced the final version of the article.

Funding SAEP is supported by a Niels Stensen Fellowship. MW is supported by an Australian National Health and Medical Council research fellowship.

Competing interests None.

Ethics approval UK Biobank has obtained Research Tissue Bank approval from its governing Research Ethics Committee, as recommended by the National Research Ethics Service. Permission to use the UK Biobank Resource was approved by the Access Sub-Committee of the UK Biobank Board.

Provenance and peer review Not commissioned; externally peer reviewed.

Data sharing statement The UK Biobank Resource holds the data used in this article.

Open Access This is an Open Access article distributed in accordance with the Creative Commons Attribution Non Commercial (CC BY-NC 4.0) license, which permits others to distribute, remix, adapt, build upon this work noncommercially, and license their derivative works on different terms, provided the original work is properly cited and the use is non-commercial. See: http:// creativecommons.org/licenses/by-nc/4.0/

\section{REFERENCES}

1. Peto R, Lopez AD, Boreham J, et al. Mortality from tobacco in developed countries: indirect estimation from national vital statistics. Lancet 1992;339:1268-78.

2. Eriksen M, Mackay J, Ross H. The tobacco atlas. 4th edn. Atlanta, GA: American Cancer Society; New York, NY:World Lung Foundation, 2012

3. World Health Organization. Women and the tobacco epidemic: challenges for the 21st century. Geneva: World Health Organization, 2001.

4. WHO Report on the Global Tobacco Epidemic, 2008: the MPOWER package. Geneva: World Health Organization, 2008.

5. Lopez AD, Collishaw NE, Piha T. A descriptive model of the cigarette epidemic in developed countries. Tob Control 1994;3:242-7.

6. Huxley R, Jamrozik K, Lam TH, et al. Impact of smoking and smoking cessation on lung cancer mortality in the Asia-Pacific region. Am J Epidemiol 2007;165:1280-6.

7. Huxley RR, Woodward M. Cigarette smoking as a risk factor for coronary heart disease in women compared with men: a systematic review and meta-analysis of prospective cohort studies. Lancet 2011;378:1297-305.

8. Peters SA, Woodward M, Huxley RR. Smoking as a risk factor for stroke in women compared with men: a meta-analysis. Stroke 2013;44:2821-8.

9. Prescott E, Hippe M, Schnohr P, et al. Smoking and risk of myocardial infarction in women and men: longitudinal population study. BMJ 1998;316:1043-7.

10. Prescott E, Bjerg AM, Andersen PK, et al. Gender difference in smoking effects on lung function and risk of hospitalization for COPD: results from a Danish longitudinal population study. Eur Respir J 1997;10:822-7.

11. Feigin V, Parag V, Lawes CM, et al. Smoking and elevated blood pressure are the most important risk factors for subarachnoid hemorrhage in the Asia-Pacific region: an overview of 26 cohorts involving 306,620 participants. Stroke 2005;36:1360-5.

12. Woodward M, Tunstall-Pedoe H, Smith WC, et al. Smoking characteristics and inhalation biochemistry in the Scottish population. J Clin Epidemiol 1991;44:1405-10.

13. Giovino GA, Mirza SA, Samet JM, et al. Tobacco use in 3 billion individuals from 16 countries: an analysis of nationally representative cross-sectional household surveys. Lancet 2012;380:668-79.

14. Woodward M, Lam TH, Barzi F, et al. Smoking, quitting, and the risk of cardiovascular disease among women and men in the Asia-Pacific region. Int J Epidemiol 2005;34:1036-45.

15. Centers for Disease Control and Prevention (CDC). Cigarette smoking among adults-United States, 2004. MMWR Morb Mortal Wkly Rep 2005;54:1121-4.

16. Allen N, Sudlow C, Downey $P$, et al. UK Biobank: current status and what it means for epidemiology. Health Policy Technol 2012;1:123-6.

17. UK Biobank: Protocol for a large-scale prospective epidemiological resource. 2007. (cited 16 March 2014). http://www ukbiobank ac uk/ wp-content/uploads/2011/11/UK-Biobank-Protocol pdf

18. Townsend material deprivation score for output areas in Englandbased on Census 2001. 2004. (cited 16 March 2014). http://www erpho org uk/ViewResource aspx?id=9070

19. R: A Language and Environment for Statistical Computing [ Vienna, Austria: R Foundation for Statistical Computing; 2013.

20. Freedman ND, Leitzmann MF, Hollenbeck AR, et al. Cigarette smoking and subsequent risk of lung cancer in men and women: analysis of a prospective cohort study. Lancet Oncol 2008;9:649-56.

21. Lifestyle Statistics Health and Social Care Information Centre. Statistics on Smoking: England, 2013. 2013. (cited 6 March 2014). http://www hscic gov uk/catalogue/PUB11454/smok-eng-2013-rep pdf

22. Huxley RR, Yatsuya H, Lutsey PL, et al. Impact of age at smoking initiation, dosage, and time since quitting on cardiovascular disease in African Americans and whites: the atherosclerosis risk in communities study. Am J Epidemiol 2012;175:816-26.

23. $\mathrm{Ng} \mathrm{M}$, Freeman MK, Fleming TD, et al. Smoking prevalence and cigarette consumption in 187 countries, 1980-2012. JAMA 2014;311:183-92.

24. Hitchman SC, Fong GT. Gender empowerment and female-to-male smoking prevalence ratios. Bull World Health Organ 2011;89:195-202.

25. Kiyohara C, Ohno Y. Sex differences in lung cancer susceptibility: a review. Gend Med 2010;7:381-401.

26. Rivera MP, Stover DE. Gender and lung cancer. Clin Chest Med 2004:25:391-400.

27. Gasperino J, Rom WN. Gender and lung cancer. Clin Lung Cancer 2004;5:353-9. 
28. Mollerup S, Ryberg D, Hewer A, et al. Sex differences in lung CYP1A1 expression and DNA adduct levels among lung cancer patients. Cancer Res 1999;59:3317-20.

29. Ryberg D, Hewer A, Phillips DH, et al. Different susceptibility to smoking-induced DNA damage among male and female lung cancer patients. Cancer Res 1994;54:5801-3.

30. Wei $\mathrm{Q}$, Cheng $\mathrm{L}, \mathrm{Amos} \mathrm{Cl}$, et al. Repair of tobacco carcinogen-induced DNA adducts and lung cancer risk: a molecular epidemiologic study. J Natl Cancer Inst 2000;92:1764-72.

31. Guinee DG Jr, Travis WD, Trivers GE, et al. Gender comparisons in human lung cancer: analysis of p53 mutations, anti-p53 serum antibodies and C-erbB-2 expression. Carcinogenesis 1995; 16:993-1002.
32. Tang DL, Rundle A, Warburton D, et al. Associations between both genetic and environmental biomarkers and lung cancer: evidence of a greater risk of lung cancer in women smokers. Carcinogenesis 1998; 19:1949-53.

33. Marrogi AJ, Mechanic LE, Welsh JA, et al. TP53 mutation spectrum in lung cancer is not different in women and men. Cancer Epidemiol Biomarkers Prev 2005;14:1031-3.

34. Stabile LP, Davis AL, Gubish CT, et al. Human non-small cell lung tumors and cells derived from normal lung express both estrogen receptor alpha and beta and show biological responses to estrogen. Cancer Res 2002;62:2141-50.

35. Sieminska A, Jassem E. The many faces of tobacco use among women. Med Sci Monit 2014:20:153-62. 